\title{
Control of Feline Leukaemia Virus
}

\author{
K. WEIJER ${ }^{1}$, F.G.C.M. UYTDEHAAG ${ }^{2}$ and A.D.M.E. OSTERHAUS ${ }^{2}$ \\ ${ }^{1}$ The Netherlands Cancer Institute, Division of Immunology, Plesmanlaan 121, 1066 CX \\ Amsterdam (The Netherlands) \\ ${ }^{2}$ National Institute of Public Health and Environmental Protection, Department of \\ Immunobiology, P.O. Box 1, 3720 BA Bilthoven (The Netherlands)
}

\begin{abstract}
Weijer, K., UytdeHaag, F.G.C.M. and Osterhaus, A.D.M.E., 1989. Control of feline leukaemia virus. Vet. Immunol. Immunopathol., 21: 69-83.
\end{abstract}

Feline leukaemia virus (FeLV) usually occurs in its natural species, the domestic cat. FeLV is also important to human individuals as a comparative model, as it may cause a variety of diseases, some malignant and some benign, such as immunosuppression, which bears a resemblance to AIDS (acquired immune deficiency syndrome) in man.

FeLV is transmitted among cats by contagion. The main sources of infection are persistently infected carrier cats which continuously excrete virus. Dissemination of FeLV among cats may be prevented by identifying infected carrier cats and removing them from contact with non-infected cats. Removal programmes using indirect immunofluorescence antibody tests were applied successfully in The Netherlands. The proportion of FeLV-positive cats decreased from $9 \%$ in 1974 to approximately $3 \%$ in 1985 during such a programme. The results of a removal programme carried out in a catbreeders' society were even better: the incidence of cats positive for FeLV decreased from $11 \%$ in 1974 to less than $2 \%$ within 4 years. None of the cats tested in this society has been found to be positive for FeLV since 1984.

Besides removal programmes, other methods of control, such as pre-exposure treatment, were developed to prevent the spread of $\mathrm{FeLV}$. We attempted to protect kittens against oronasal infection with FeLV by treatment with virus-neutralizing (VN) monoclonal antibodies (MoAbs) directed against an epitope on the viral glycoprotein gp70. However, no protection was achieved. It is unlikely that the amount of VN antibodies, the mode and route of their application or the infectious dose of FeLV used can account for this failure. Other possible explanations for the lack of protective effect are that (i) the restricted epitope specificity of the MoAb preparation used may have led to selection of neutralization-resistant virus mutants, or (ii) other mechanisms than virus neutralization (complement-mediated lysis, antibody-dependent cell cytotoxicity), that may be involved in protection, function less efficiently with MoAb. However, in the light of our finding that an early anti-idiotypic response is observed in all cats following administration of the MoAb preparation, the rapid clearance of anti-FeLV MoAb from the circulation is a more likely explanation.

Efforts were further made to develop a vaccine for controlling FeLV infection. The immunostimulating complex vaccine (FeLV-ISCOM vaccine), a subunit vaccine in which FeLV gp70 is presented in a particular manner, looks promising. The protective effect of FeLV-ISCOM vaccine was studied by vaccinating six 8-week-old SPF cats with ISCOM, followed by oronasal challenge 
with FeLV. Six unvaccinated cats were also challenged with the same dose of FeLV. The vaccinated cats developed FeLV serum antibodies, some of which were directed to the shared epitope on gp70. At 10 weeks after challenge, none was viraemic, whereas four of the control cats had developed FeLV viraemia. The potential of FeLV-ISCOM vaccine to induce protective immunity in cats against FeLV was also shown in a field experiment.

The generation of an anti-idiotype vaccine was another approach to developing a FeLV vaccine. Virus-neutralizing mouse monoclonal antibodies were generated against an epitope of FeLV gp 70 . Against one of these, MoAb 3-17, a panel of 15 anti-idiotype monoclonal antibodies (MoAb2) was generated. They recognized partially overlapping private idiotypes within the paratope of MoAb 3-17. Repeated immunization with these MoAb2 coupled to keyhole limpet haemocyanin (KLH) resulted in low-titered anti-FeLV serum titers in BALB/c mice.

In a second series of experiments, rabbits were immunized with an affinity-purified polyclonal cat anti-FeLV neutralizing antibody preparation. Immunization of BALB/c mice with Ig from these rabbits resulted in high anti-FeLV antibody titers within 3 weeks.

\section{INTRODUCTION}

Feline leukaemia virus (FeLV), identified by Jarrett et al. (1964a,b) in 1964 is an important pathogen in cats and is probably the major nontraumatic cause of death in adult animals (Jarrett, 1985). The virus is widely distributed in cat populations, also in The Netherlands (Weijer and Daams, 1976), and causes a variety of diseases including haemopoietic tumours (lymphosarcoma/leukaemia), non-malignant haemopoietic diseases (immunosuppression and anaemia) and reproductive diseases (infertility and abortion). Because of the anti-proliferative syndromes such as aplastic anaemia and fatal immunodeficiency disease, FeLV provides an important paradigm for human AIDS, induced by the human immunodeficiency virus (HIV) (Wong-Staal and Gallo, 1985; Overbaugh et al., 1988). The control of virus diseases still depends largely on epidemiologic measures, including the application of vaccination strategies. Apart from pre-exposure immunoprophylaxis, there is also a serious need for specific post-exposure treatment. In the present paper we give an overview of these subjects, supplemented with recent data derived from our research in this field.

\section{EPIDEMIOLOGIC MEASURES}

It was found by Hardy et al. (1973) and Jarrett et al. (1973) that FeLV is transmitted contagiously among cats. The main source of infection is the persistently infected FeLV carrier-cat which excretes virus continuously from the mouth and in other secretions (Jarrett et al., 1973; Francis et al., 1977).

Although much infectious virus may be present in the saliva, direct contact is usually required for the transmission of the virus. This explains why the incidence of FeLV-related diseases is higher in cats kept in closed multicat households than in free-range cats. Consequently, FeLV-related diseases are 
more frequently diagnosed in pedigree cats which are usually maintained in larger groups.

Since control programmes aim at consistently destroying persistently viraemic cats, methods of diagnosing FeLV infection must be accurate. Until recently, the two methods most widely used to routinely diagnose FeLV-infection were virus isolation from plasma samples (Jarrett et al., 1968) and immunofluorescence carried out on blood smears (Hardy et al., 1973). These tests have been shown to give comparable results (Jarrett et al., 1982a). Recently, a third method which detects FeLV p27 antigen, has become available. This is an enzyme-linked immunosorbent assay (ELISA) that can be performed directly by veterinary surgeons.

The spread of FeLV among cats can be prevented by detecting infected carrier cats and removing them from contact with uninfected cats. Removal programmes based on seropositivity in indirect immunofluorescence antibody (IFA) tests on air-dried blood smears have been used successfully in veterinary medicine for the past 12 years (Hardy et al., 1976; Weijer and Daams, 1978; Weijer et al., 1986a). Hardy et al. (1976) showed that when FeLV carrier cats were removed from non-infected animals, these households became free from FeLV infection, in contrast to similar multicat households where no such removal programme was implemented. This demonstrated for the first time that it was possible to prevent the contagious spread of a mammalian oncornavirus in the natural environment.

In a similar European study, we showed that essentially the same results were obtained in a removal programme (Weijer et al., 1986a). In the period 1974-1986, 47070 blood smears from Dutch cats were examined by IFA. About $20 \%$ of the blood smears came from cats suspected of FeLV-related disease. The remaining $80 \%$ came from cats participating in the removal programme. The results of this removal programme are depicted in Fig. 1. There was a decrease in the percentage of FeLV-positive cats from about $9 \%$ in 1974 to about $3 \%$ in 1986.

In the same period the removal programme was carried out among cats belonging to members of the Dutch cat breeders' society "Felikat", in which the programme was imposed on all the members. The results of this programme, in which more than 8000 blood smears were tested, are depicted in Fig. 2. The incidence of FeLV-positive cats decreased from over $11 \%$ in 1974 to less than $2 \%$ within 4 years. Since 1984 none of the cats tested within this society has proved to be FeLV-positive. Taken together, these data strongly suggest that the percentage of FeLV-carrier cats in a cat population can be reduced dramatically by a removal programme in which $\mathrm{FeLV}$-positive cats are traced by IFA, carried out on blood smears, and by subsequent prevention of further contacts of negative cats with these positive animals. From these results it can also be deduced that the conclusion of Pacitti (1987), that latently infected cats do not play a major role in maintaining the infection in cat populations, is probably correct. 


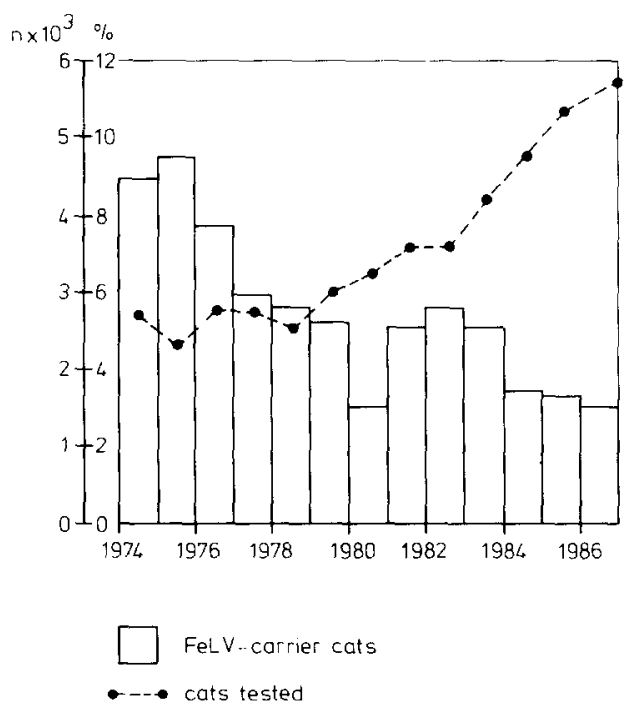

Fig. 1. FeLV status of Dutch cats during a removal programme.

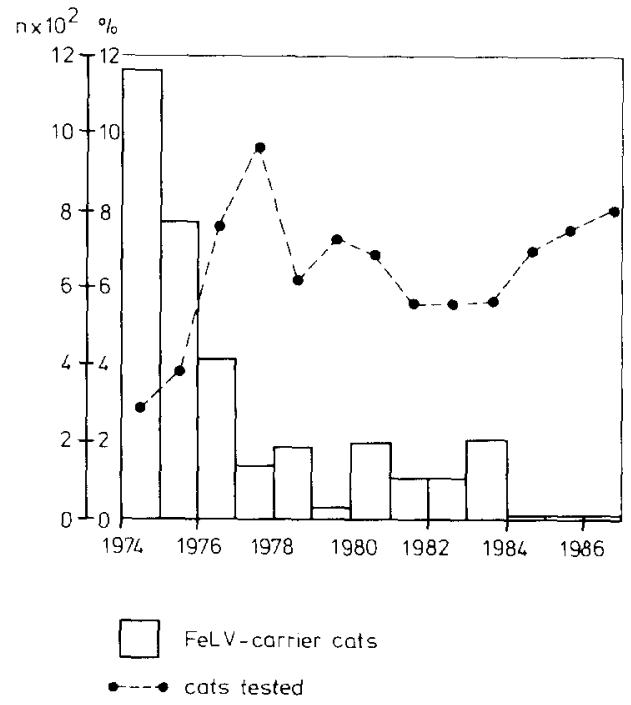

Fig. 2. FeLV status of cats in a large Dutch catbreeders' society (Felikat) during a removal programme.

\section{POST-EXPOSURE TREATMENT IN A RETROVIRUS SYSTEM}

In the absence of an effective and safe vaccine against certain retrovirus infections of mammals, including HIV in man, there is an urgent need for specific post-exposure treatment. Polyclonal xenogeneic or allogeneic antibod- 
ies to FeLV gp70 with neutralizing activity are protective in cats when administered through the colostrum (Hoover et al., 1977), or by systemic inoculation, provided that administration occurs within 6 days of exposure (De Noronha et al., 1977; Cotter et al., 1980; Haley et al., 1985 ).

Because protection from viraemia is believed to be mediated at least partly by virus-neutralizing (VN) antibody directed against the envelope glycoprotein gp70 of FeLV (Russell and Jarrett, 1978), passive immunization with neutralizing monoclonal antibodies against FeLV of subgroups $\mathrm{A}, \mathrm{B}$ and $\mathrm{C}$ would appear to be a promising approach for the protection of cats after FeLV infection.

In our post-exposure treatment experiment, ten 9-week-old female cats, divided into five groups of two, were used. All cats were infected oronasally on day 0 with $10^{6}$ focus-forming units (ffu) of FeLV-A/Glasgow-1. All cats were immunized i.m. with $1 \mathrm{ml} / \mathrm{kg}$ body weight of a mixture of MoAbs 3-17 and 6$15(3 \mathrm{mg} / \mathrm{ml} \mathrm{Ig})$ every 2 days over a 20 -day period. Treatment of the first two cats started on day 0 , the day of virus infection, and that of the other groups on days 10,20,30 or 40 after virus infection. Blood samples were collected every 10 days except during the application period of the MoAbs when samples were taken every 2 days. Serological tests were carried out essentially as described previously (Osterhaus et al., 1985; Weijer et al., 1986b). The results of the serology are summarized in Fig. 3.

No protection against oronasal FeLV-A infection was achieved since nine out of ten cats developed persistent viraemia after virus challenge (Fig. 3A). Previous studies (Jarrett et al., 1982b) had shown that oronasal infection with this dose of virus in kittens of this age could be expected to result in viraemia in about $85 \%$ of the cats. Our results contrast sharply with those of similar post-exposure passive immunization experiments carried out with xenogeneic or allogeneic polyclonal neutralizing anti-FeLV antibodies, in which a protective effect was observed (De Noronha et al., 1977; Hoover et al., 1977; Cotter et al., 1980; Haley et al., 1985). The amount of virus-neutralizing antibodies, the mode and moment of their application, and the infection dose of FeLV used, do not differ essentially from those used in the above studies and thus should not account for the observed discrepancy. Various other explanations may, however, be proposed.

First, the xenogeneic MoAbs may be rapidly cleared from the circulation through the generation of anti-mouse Ig antibodies. Fig. 3D shows that the appearance of anti-mouse Ig antibodies correlates with the disappearance of the MoAbs (Fig. 3C) used. This may have occurred in our studies, since the presence of aggregated $\operatorname{IgG}$ in the inoculated materials was not investigated. Rapid clearance of administered IgG has been reported in studies using MoAbs for treatment of human cancer patients and against rejection of allografts (Miller et al., 1982; Gratama et al., 1984). From these and other studies it is clear that, apart from the expected anti-isotypic and anti-allotypic response, a 


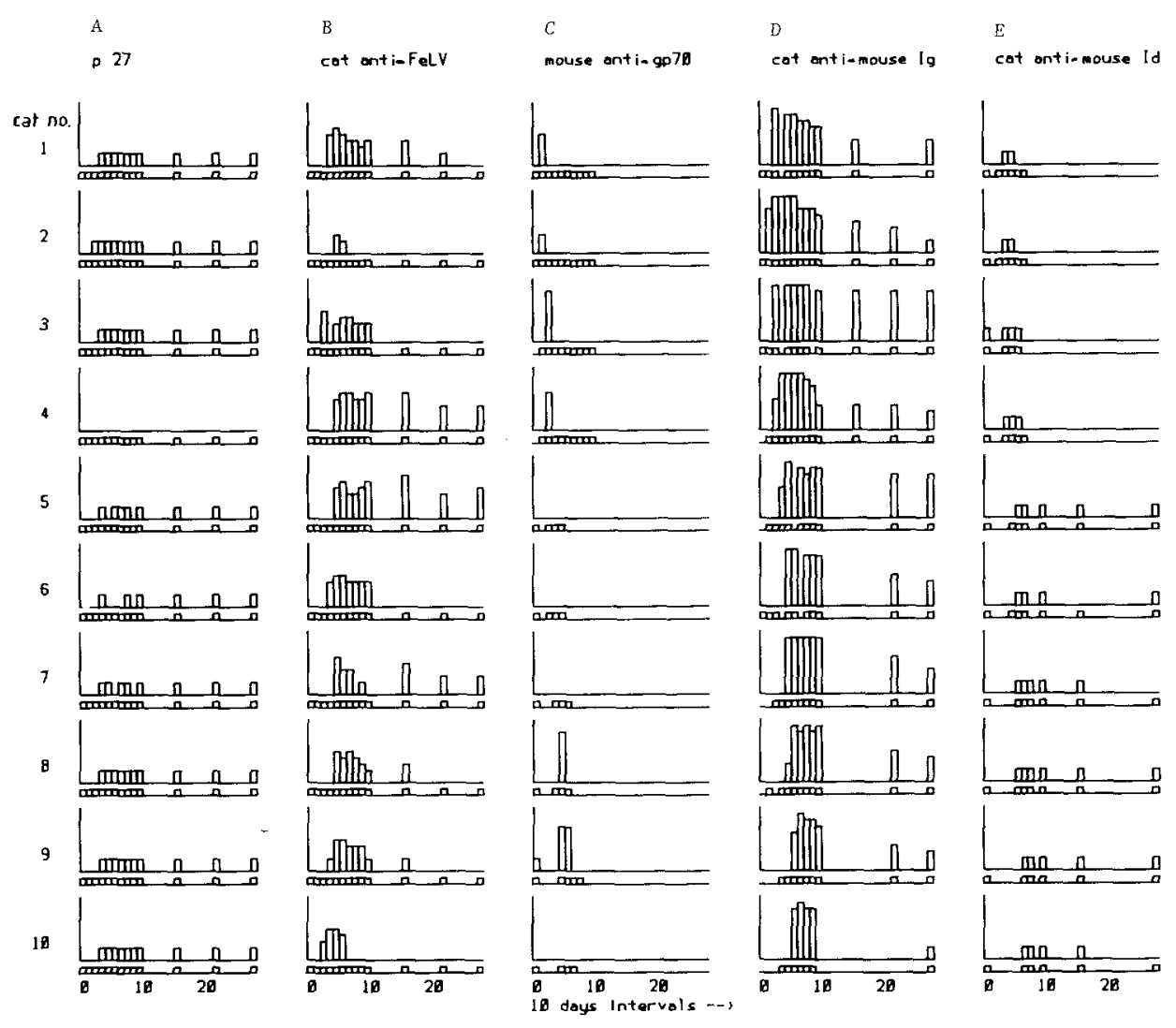

Fig. 3. Serology of ten cats in the passive immunization experiment.

A: Immunofluorescence test for the detection of FeLV p27 (bar, positive; no bar, negative).

B: Whole-virus (FL74) ELISA for the detection of feline antibodies directed against FeLV, using an HRP-labelled rabbit anti-cat Ig preparation as conjugate $\left(\log _{10}\right.$ titer: $\left.0.5-4.5\right)$.

C: Whole-virus (FL74) ELISA for the detection of MoAbs 3-17/6-15 (murine MoAbs directed against $\mathrm{FeLV}$ gp 70 ) using an HRP-labelled goat anti-mouse Ig preparation as conjugate $\left(\log _{10}\right.$ titer: $0.5-4.5$ ).

D: ELISA for the detection of antibodies directed against mouse Ig determinants ( $\log _{10}$ titer: 0.5 $4.5)$.

E: Cross-linking ELISA for the detection of feline anti-idiotypic antibodies (bar means titer higher than $0.5 \log _{10}$; no bar means titer lower than $0.5 \log _{10}$ ).

Blood samples were taken on days $10,20,30,40,50,61,72,80,89,150,192$ and 234 . The serology of the samples taken during the application period of MoAbs is not included in this figure. (Open squares: time of sampling.)

vigorous anti-idiotypic response could also be responsible for this phenomenon. This anti-idiotypic reaction is probably the dominant aspect of the immune response to multiple infusions of murine MoAb (Shawler et al., 1985). We also found that, apart from an anti-mouse IgG1 activity in cats, an anti- 
idiotypic response was present shortly after initiation of treatment (Fig. 3E). These data support our hypothesis that administration of MoAb elicits a more vigorous anti-idiotypic response than polyclonal antibody, due to the presentation of only a limited set of idiotopes (UytdeHaag and Osterhaus, 1985). This potential drawback, namely a rapid clearance as a consequence of an antiidiotypic response, may possibly be overcome by the use of predefined mixtures of MoAbs resulting in a more heterogeneous set of idiotypic determinants.

A second explanation for the different results might be the restricted epitope specificity of the MoAb preparation used, which may have produced a neutralization-resistant mutant selection. This could be overcome by using panels of MoAbs directed against different epitopes of the viral glycoprotein. In this respect we have shown that at least two virus-neutralization-inducing epitopes are present on the viral glycoprotein of FeLV of subgroups $\mathrm{A}, \mathrm{B}$ and $\mathrm{C}$ (Weijer et al., 1986b ).

A third explanation could be the (sub)class of antibody used in our experiment (subclass IgG1). At present it is not clear to what extent the results obtained in the FeLV system are influenced by phenomena related to effective functions of different mouse antibody classes in the cat.

Finally, it is emphasized that the protection achieved with polyclonal antiFeLV post-exposure treatment may not have been due solely to virus neutralization. This might in fact be less efficient in combination with MoAbs, but other mechanisms such as antibody-dependent cellular cytotoxicity, complement-mediated lysis and macrophage enhancement may also have played a role (Tax et al., 1983).

\section{PREVENTIVE VACCINATION}

It seems a good strategy to develop a FeLV vaccine that induces virus-neutralizing (VN) antibodies directed against FeLV gp 70 because these antibodies may protect cats from viraemia (Russell and Jarrett, 1978). However, conventional vaccines based upon (a) whole live-attenuated viruses or (b) inactivated viruses still present major problems (Norrby, 1983).

The following approaches were considered for developing a FeLV vaccine.

(a) Whole live-attenuated virus vaccine. Attenuated virus strains may reverse to virulence, may be too pathogenic for immune-deficient individuals, cannot be used in the presence of natural antibody and may be prevented from replication by interference mechanisms. In the FeLV system, whole live-attenuated virus vaccines are capable of inducing VN antibodies (Jarrett et al., 1974), but in one study, one out of nine cats vaccinated with such a vaccine developed a FeLV-negative lymphosarcoma 6 years after vaccination (Hardy, 1981). Thus, live FeLV virus vaccines may be too dangerous to use, possibly due to the fact that the viral genome may be integrated in the host cell DNA. A more effective 
live vaccine might perhaps be developed with the aid of genetic engineering. A part of FeLV, for example FeLV gp70, could be inserted into the genome of a vector such as vaccinia virus and this construct might then be used as a vaccine. Apart from a humoral and cell-mediated immunity against the vector, immunity against FeLV gp70 is also induced and this may protect cats against FeLV infection. A disadvantage of this approach is the pathogenicity of the vector itself and its potential for spreading among non-vaccinated individuals.

(b) Inactivated virus vaccine. Various approaches have been considered for the vaccination of cats against FeLV infection with inactivated vaccines. However, most of these were not successful or proved only of limited value. Not only the use of these inactivated vaccines but also of subunit and synthetic peptide vaccines, which include only those components of the virus known to elicit the desired immune response, is greatly hampered by the lack of adequate systems for their immunogenic presentation (Olsen et al., 1976, 1977; Pedersen et al., 1978). Lewis et al. (1981) described a subunit vaccine containing FeLV gp70 that elicited a certain degree of protection against FeLV-infection in the absence of the induction of VN antibody. This subunit vaccine was the prototype vaccine of the now commercially available FeLV vaccine Leukocell ${ }^{R}$ (Norden Laboratories; Sharpee et al., 1986).

Recently we described the induction of a protective immune response in cats against feline leukaemia virus infection with a novel structure for the antigenic presentation of membrane proteins: the immunostimulating complex (ISCOM) (Morein et al., 1984). ISCOM containing the gp70/85 of FeLV not only induced virus-neutralizing antibodies in cats, but also protection against infection after oronasal challenge with the virus (Osterhaus et al., 1985). No (VN) antibodies could be detected in the control cats. Results of this vaccination experiment are summarized in Table 1. After challenge, four out of six control cats became viraemic, while all vaccinated cats were protected against FeLV infection. That only four of six cats became viraemic during the course of the experiment is in accordance with what was to be expected on the basis of the challenge dose used and the age of the kittens at the day of challenge (Hoover et al., 1976; Jarrett et al., 1982b).

To assess the potential of the commercial feline leukaemia virus vaccine Leukocell ${ }^{\mathrm{R}}$ and a candidate subunit ISCOM FeLV vaccine (Osterhaus et al., 1985 ) for inducing protective immunity in cats against FeLV infection under field conditions, we conducted a comparative trial in three groups of privately owned cats, kept under conventional conditions in single or multiple cat households (Osterhaus et al., 1987a). Two groups of animals were vaccinated three times either with Leukocell ${ }^{\mathrm{R}}$ or with the candidate ISCOM vaccine, both containing about the same amount of FeLV envelope glycoprotein (gp70). The third group was inoculated at the same intervals with a control preparation not containing FeLV antigen. Serological responses were measured with an 
TABLE 1

Detection of viraemia and serologic response of cats vaccinated with FeLV/F422 ISCOM

\begin{tabular}{|c|c|c|c|c|c|c|c|c|c|c|c|c|c|c|c|c|}
\hline & \multicolumn{3}{|c|}{ Day 0} & \multicolumn{3}{|c|}{ Day 21} & \multicolumn{3}{|c|}{ Day 35} & \multicolumn{3}{|c|}{ Day 43} & \multirow{2}{*}{$\begin{array}{l}\text { Day } \\
61 \\
\frac{\mathrm{V}^{\mathrm{d}}}{}\end{array}$} & \multirow{2}{*}{$\begin{array}{l}\text { Day } \\
75 \\
V\end{array}$} & \multirow{2}{*}{$\begin{array}{l}\text { Day } \\
111 \\
\mathrm{~V}\end{array}$} & \multirow{2}{*}{$\begin{array}{l}\text { Day } \\
113 \\
\mathrm{~V}\end{array}$} \\
\hline & $\mathrm{E}^{\mathrm{a}}$ & $\mathrm{CE}^{\mathrm{b}}$ & $\mathrm{VN}^{c}$ & $\mathrm{E}$ & $\mathrm{CE}$ & $\mathrm{VN}$ & $\mathrm{E}$ & $\mathrm{CE}$ & $\mathrm{VN}$ & $\mathrm{E}$ & $\mathrm{CE}$ & $\mathrm{VN}$ & & & & \\
\hline $\mathrm{A} 1^{e}$ & - & - & - & 1.5 & 14 & - & 3.5 & 44 & + & 3.5 & 43 & + & - & - & - & 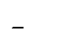 \\
\hline 2 & - & - & - & 1.5 & - & - & 3.5 & 32 & - & 3.5 & 23 & - & - & - & - & - \\
\hline 3 & - & - & - & 1 & - & - & 3.5 & 24 & - & 3.5 & 17 & + & - & - & - & - \\
\hline 4 & - & - & - & 1.5 & 8 & - & 4 & 19 & - & 3.5 & 25 & - & - & - & - & - \\
\hline 5 & - & - & - & 2 & 9 & - & 3.5 & 38 & + & 4 & 26 & + & - & - & - & - \\
\hline 6 & - & - & - & - & - & - & 3 & 24 & + & 3.5 & 17 & + & - & - & - & - \\
\hline$B 1^{r}$ & - & - & - & - & - & - & - & - & - & - & - & - & - & - & - & - \\
\hline 2 & - & - & - & - & - & - & - & - & - & - & - & - & - & - & + & + \\
\hline 3 & - & - & - & - & - & - & - & - & - & - & - & - & - & - & - & - \\
\hline 4 & - & - & - & - & - & - & - & - & - & - & - & - & - & + & + & + \\
\hline 5 & - & - & - & - & - & - & - & $\mathrm{ND}^{\mathrm{g}}$ & - & - & - & - & - & + & + & + \\
\hline 6 & - & - & - & - & - & - & - & - & - & - & - & - & - & - & - & + \\
\hline
\end{tabular}

${ }^{a} \mathrm{E}=$ ELISA $(\log 10) ;(-=<1)$.

${ }^{\mathrm{b}} \mathrm{CE}=$ anti-gp/70/85 competition ELISA (\%); less than $5 \%$ reduction was considered negative.

' $\mathrm{VN}=$ virus neutralization; less than 2 was considered negative.

${ }^{\mathrm{d}} \mathrm{V}=$ viraemia $(+=\mathrm{IF}$, and Leukassay-F-positive $)$.

'A $1-6=$ vaccinated cats.

${ }^{ } \mathrm{B} 1-6=$ unvaccinated cats.

${ }^{\mathrm{k}} \mathrm{ND}=$ not done.

enzyme-linked immunosorbent assay, a membrane immunofluorescence test (MIF) and in a virus-neutralization test, described earlier by Weijer et al. (1986b), before (day 0) and after vaccination (day 100).

From our vaccination experiments we learned that a FeLV ISCOM candidate vaccine prepared from conventionally produced $\mathrm{FeLV}$, containing $3 \mu \mathrm{g}$ of gp70/85 in a three-dose regimen, protects cats against FeLV infection and is highly effective in inducing anti-FeLV antibodies in cats under field conditions. The antibody response as measured in ELISA, MIF, VN (Fig. 4) and western blotting assays, proved superior to the commercially available conventionally adjuvanted inactivated whole virus vaccine Leukocell ${ }^{R}$. A pronounced booster effect was further seen in the respective assays of cats seropositive at day 0 in ELISA. Therefore ISCOM preparations might be especially valuable in studies such as recently proposed by Gibbs et al. (1988) and Levine et al. (1988). In these, an inactivated conventionally adjuvanted HIV vaccine would be used to boost the specific immune response in clinically healthy seropositives with the aim of gaining additional protection against the development of clinical symptoms of HIV infection. Although such experiments under field conditions cannot prove that extra protection is induced by immunization, the 


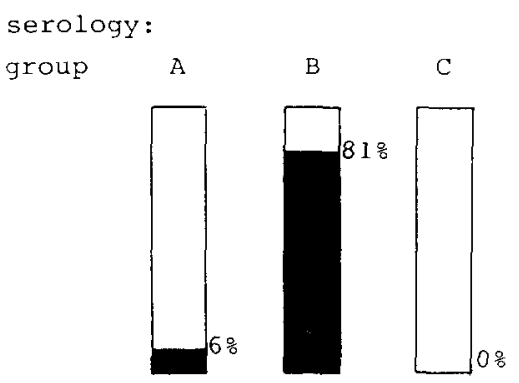

Fig. 4. Antibody titer rise measured in virus neutralization tests. A: Leukocell ${ }^{\mathrm{R}}$; B: ISCOM; C: control.

serological data indicate that this is highly likely for the majority of ISCOMvaccinated cats since the presence of $\mathrm{VN}$ antibody, even at very low titers, will apparently protect the cat from natural infection (Russell and Jarrett, 1978). Even if VN antibody fails to develop, some protective effect results (Osterhaus et al., 1985) so that other explanations for this protection should also be considered.

All these data thus suggest that the ISCOM method of antigenic presentation could be of great value in the construction of safe and effective nucleicacid-free retrovirus vaccines, and justify efforts towards the development of a candidate ISCOM retrovirus vaccine.

\section{ANTI-IDIOTYPIC ANTIBODIES AS IMMUNOGENS}

Recent studies using the network concept of the immune system initially proposed by Jerne (1974), indicate that elements of the immune system itself, e.g. anti-idiotype (anti-id) antibodies, can replace "external" antigens in vaccination. The basis of this concept is the mutual recognition of variable (V) domains of the elements of the immune system which form a continually communicating web of idiotypes and anti-idiotypes. The amino acid sequence in the $\mathrm{V}$ region of an immunoglobulin determines the three-dimensional configuration of its antigen-containing site and permits it to react with a certain epitope on a particular antigen or with a certain idiotope located within a particular idiotype. An antibody (Ab 1) response upon injection with an antigen or an antibody (Ab1) itself results in an anti-Id (Ab2) response recognizing idiotypes of the $\mathrm{Ab} 1$. This in turn will elicit an $\mathrm{Ab} 3$ response regulating the $\mathrm{Ab} 2$ response by recognizing its idiotype specificities, since an Ab2 may react with the antigen-binding site within the $\mathrm{V}$ region of $\mathrm{Ab1}$ on the basis of a structural complement and represent a three-dimensional internal image of the epitope on the external antigen. Consequently, the administration of $\mathrm{Ab2}$ can trigger the immune system into expanding a population of Ab3-producing cells that not only bind to Ab2 but also to antigen. Ab2 can therefore probably replace antigen for vaccination purposes. 
In the following pages we will review our data (UytdeHaag et al., 1986; Osterhaus et al., 1987b; Weijer et al., 1988) which clearly show that anti-idiotypic antibodies (Ab2) in the feline leukaemia virus system are indeed capable of inducing antiviral immunity. They also indicate that this capacity is not restricted to Ab2 displaying the properties of true internal images. Various strategies using xenogeneic or allogeneic polyclonal and monoclonal Ab2 were explored.

To generate an anti-Id vaccine, a panel of mouse monoclonal antibodies (Ab1) was prepared against FeLV gp70 as described previously (Weijer et al., $1986 \mathrm{~b})$. For the production of panel of MoAb2, BALB/c mice were immunized with MoAb1 as described earlier (Osterhaus et al., 1988). Fifteen stable MoAb2producing hybridomas were obtained. After inhibition experiments, we concluded that all MoAb2 were directed against private idiotypes of MoAb1. In competition studies it was shown that these MoAb2 recognized two different, partially overlapping idiotopes in the paratope of MoAb1, 3-17 (Table 2).

$\mathrm{Ab} 2 \alpha$ with specificity for either interstrain, recurrent or private idiotopes, have been shown capable of eliciting the synthesis of Ab3 responses with predefined Ab1-like antigen specificity, even across allotype linkage or species barriers (for review see UytdeHaag et al., 1986). Using a selection of these MoAb2 in several immunization protocols, we therefore tried to induce activity of Ab3 sharing MoAb1, 3-17 anti-FeLV in BALB/c mice. In an initial experiment, 1 out of 20 mice immunized with $10 \mu \mathrm{g}$ of MoAb2 developed a low level of anti-FeLV antibody in an ELISA. This indicates that silent idiotypes of predefined antigen specificity may, in the absence of antigen, be induced by Ab2 defining a private paratope-related idiotope on MoAb1. Encouraged by the work of Legrain et al. (1985) and Sanchez and Legrain (1985), in which $\mathrm{Ab} 3$ were induced by sequential immunization with two different Ab2, we started a second series of experiments. In these, seven groups of five mice were immunized four times at 14-day intervals either with $50 \mu \mathrm{g}$ of the same KLH-

TABLE 2

Characteristics of MoAb2

\begin{tabular}{|c|c|c|c|c|c|}
\hline & MoAb2 & & & Specificity & $\begin{array}{l}\text { Inhibition of binding } \\
\text { of MoAb2, } 2-17-\mathrm{HRP} \\
\text { to MoAb1, } 3-17\end{array}$ \\
\hline Group I & $\begin{array}{l}2-17 \\
1 \mathrm{C} \\
14 \mathrm{~B}\end{array}$ & $\begin{array}{r}1 \mathrm{~A} \\
8 \mathrm{~B} \\
15 \mathrm{C}\end{array}$ & $\begin{array}{l}21 \mathrm{~A} \\
12 \mathrm{~B} \\
19 \mathrm{~B}\end{array}$ & $\begin{array}{l}\text { Private } \\
\text { and } \\
\text { paratope-related }\end{array}$ & $\begin{array}{l}\text { Partial or } \\
\text { complete }\end{array}$ \\
\hline Group II & $\begin{array}{l}1 \mathrm{~B}, \\
5 \mathrm{~A},\end{array}$ & $\begin{array}{l}2 \mathrm{~A}, \\
6 \mathrm{~A},\end{array}$ & $\begin{array}{l}4 \mathrm{~B} \\
6 \mathrm{~B}\end{array}$ & $\begin{array}{l}\text { Private and } \\
\text { paratope-related }\end{array}$ & None \\
\hline
\end{tabular}


coupled MoAb2's (groups 1-6) or with different KLH-coupled MoAb2's directed against the various idiotypes of MoAb1 each time (group 7). Twelve weeks after the final immunization, 10 out of 35 mice, randomly distributed over the groups 1-7, showed anti-FeLV serum antibodies in whole virus ELISA.

In an attempt to induce antiviral immunity with polyclonal antibodies in a xenogeneic system, two rabbits were immunized four times with $100 \mu \mathrm{g}$ Ig of an affinity-purified polyclonal cat anti-FeLV neutralizing antibody (Ab1) that had been purified by protein-A Sepharose chromatography (Weijer et al., 1988). After these immunizations both rabbits exhibited a strong Ab2 response.

Twelve BALB/c mice were immunized three times (days $0,14,150$ ) with $100 \mu \mathrm{g}$ Ig, purified by protein-A Sepharose chromatography from the rabbit sera. Three weeks after the last immunization, 11 out of the 12 mice showed anti-FeLV serum antibody titers in an ELISA, while five of them also showed antibody in MIF. These results are summarized in Table 3.

Although the immune responses elicited by Ab2 were inferior to those obtained with the subunit ISCOM vaccine, one should realise that in most virus systems only $\mathrm{Ab} 2$ preparations were used that are specific for one idiotype determinant on an Ab1, with specificity for only one antigenic determinant of the virus. In several virus systems $\mathrm{Ab} 2$ was able to elicit virus-neutralizing antibody responses and T-cell-mediated responses (CTL and DTH) in the absence of antigen that seemed less MHC-restricted than those generated by antigens presented in the conventional way (for review see Osterhaus et al., 1988). The use of Ab2 preparations may also prove valuable in situations of

\section{TABLE 3}

Induction of anti-FeLV antibodies in $\mathrm{BALB} / \mathrm{c}$ mice with rabbit $\mathrm{Ab2}$

\begin{tabular}{|c|c|c|c|c|c|c|c|}
\hline \multirow{2}{*}{$\begin{array}{l}\text { Mouse } \\
\text { No. }\end{array}$} & \multirow[t]{2}{*}{$\mathrm{Ab} 2^{\mathrm{a}}$} & \multicolumn{4}{|c|}{ ELISA titer ${ }^{b}$} & \multicolumn{2}{|c|}{ MIF titer ${ }^{b}$} \\
\hline & & do & $\mathrm{d} 17$ & $\mathrm{~d} 28$ & d 170 & d 0 & $\mathrm{~d} 170$ \\
\hline 359 & Ra6 IgG & - & 10 & 30 & 300 & - & - \\
\hline 360 & Ra6 IgG & - & 100 & 100 & 1000 & - & - \\
\hline 361 & Ra6 IgG-KLH & - & 30 & 30 & 100 & - & - \\
\hline 362 & Ra6 IgG-KLH & - & 10 & 30 & 30 & - & 64 \\
\hline 363 & Ra6 IgG-pol & - & 10 & 10 & 10 & - & 16 \\
\hline 364 & Ra6 IgG-pol & - & 10 & 10 & 30 & - & 8 \\
\hline 365 & $\mathrm{Ra} 7 \mathrm{IgG}$ & - & 30 & 100 & 3000 & - & 8 \\
\hline 366 & $\mathrm{Ra} 7$ IgG & - & 10 & 30 & 1000 & - & - \\
\hline 367 & Ra7 IgG-KLH & - & 10 & 10 & 30 & - & - \\
\hline 368 & Ra7 IgG-KLH & - & 30 & 100 & 3000 & - & - \\
\hline 369 & Ra7 IgG-pol & - & 10 & 10 & 30 & - & - \\
\hline 370 & Ra7 IgG-pol & - & - & 10 & 100 & - & 32 \\
\hline
\end{tabular}

" $3 \times 100 \mu \mathrm{g}$, subcutaneously, 2nd immunization d 14, 3rd immunization d 150 .

'Sera absorbed with FEA- 0 cells $\left(0.5 \times 10^{6}\right.$ cells $\left./ \mu \mathrm{l}\right)$ and with pooled cat sera $1: 1,30 \mathrm{~min}, 37^{\circ} \mathrm{C}$. 
immune incompetence, when an individual is not able to respond adequately to a certain pathogen (Finberg and Ertl, 1986). In the future it may be possible to exploit the use of Ab2 to prevent certain undesirable (auto)immune reactions or to turn off unwanted effects of vaccines or virus infections.

\section{ACKNOWLEDGEMENTS}

The authors thank the students Ch. Bodar, J. Wagenaar and P. Overman for their contributions to the results presented, and Ms. T. van Beek, Ms. C. Kruyssen and Ms. M. Eskens for preparing the manuscript. The expert technical assistance of G. Drost, K. Siebelink and A. Pfauth is gratefully acknowledged. This work was supported in part by BV European Veterinary Laboratory EVL, Amsterdam, The Netherlands.

\section{REFERENCES}

Cotter, S.M., Essex, M., McLane, M.F., Grant, C.K. and Hardy, W.D., Jr., 1980. Chemotherapy and passive immunotherapy in naturally occurring feline mediastinal lymphoma. Dev. Cancer Res., 4: 219-226.

De Noronha, F., Baggs, R., Schäfer, W. and Bolognesi, D.F., 1977. Prevention of oncornavirusinduced sarcomas in cats by treatment with antiviral antibodies. Nature (London), 267: 5456 .

Finberg, R.W. and Ertl, H.C.J., 1986. Use of T cell-specific anti-idiotypes to immunize against viral infections. Immunol. Rev., 90: 129-155.

Francis, D.P., Essex, M. and Hardy, W.D., Jr., 1977. Excretion of feline leukaemia virus by naturally infected pet cats. Nature, 269: 252-254.

Gibbs, C.J., Mora, C., Francis, D.P., Cullman, L., Hicks, D.R. and Salk, J., 1988. Immunologic response of chimpanzees to gamma irradiated HIV emulsified in mineral oil. In: IVth International Conference on AIDS, 12-16 June 1988, Stockholm, Sweden, Abstract 6561.

Gratama, J.W., Jansen, J., Lipovich, R.A., Tanke, H.J., Goldstein, G. and Zwaan, P.E., 1984. Treatment of acute graft-versus-host disease with monoclonal antibody OKT3. Transplantation, 38: 469-474.

Haley, P.J., Hoover, E.A., Quackenbush, S.L., Gasper, P.W. and Macy, D.W., 1985. Influence of antibody infusion on pathogenesis of experimental feline leukemia virus infection. J. Natl. Cancer Inst., 74: 821-827.

Hardy, W.D., Jr., 1981. The feline leukemia virus. J. Am. Anim. Hosp. Assoc., 17: 951-956.

Hardy, W.D., Jr., Old, L.J., Hess, P.W., Essex, M. and Cotter, S.M., 1973. Horizontal transmission of feline leukaemia virus. Nature (London), 244: 266-269.

Hardy, W.D., Jr. McClelland, A.J., Zuckerman, E.E., Hess, P.W., Essex, M., Cotter, S.M., MacEwen, E.G. and Hayes, A.A., 1976. Prevention of the contagious spread of feline leukaemia virus and the development of leukaemia in pet cats. Nature (London), 263: 326-328.

Hoover, E.A., Olsen, R.G., Hardy, W.D., Jr., Schaller, J.P. and Mathes, L.E., 1976. Feline leukemia virus infection: age-related variation in response of cats to experimental infection. J. Natl. Cancer Inst., 57: 365-369.

Hoover, E.A., Schaller, J.P., Mathes, L.E. and Olsen, R.G., 1977. Passive immunity to feline leu- 
kemia. Evaluation of immunity from dams naturally infected and experimentally vaccinated. Infect. Immun., 16: 54-59.

Jarrett, O., 1985. Pathogenesis of feline leukaemia virus related diseases. In: J.M. Goldman and o. Jarrett (Editors), Mechanisms of Viral Leukaemogenesis. Churchill Livingstone, Edinburgh, $135 \mathrm{pp}$.

Jarrett, O., Laird, H.M., Hay, D. and Crighton, G.W., 1968. Replication of cat leukaemia virus in cell cultures. Nature (London), 219:521-522.

Jarrett, O., Golder, M.C. and Weijer, K., 1982a. A comparison of three methods of feline leukaemia virus diagnosis. Vet. Rec., 110: 325-328.

Jarrett, O., Golder, M.C. and Stewart, M.F., 1982b. Detection of transient and persistent feline leukaemia virus infections. Vet. Rec., 110: 225-228.

Jarrett, W.F.H., Martin, W.B., Crighton, G.W., Dalton, R.G. and Stewart, M.F., 1964a. Leukaemia in the cat. Transmission experiments with leukaemia (lymphosarcoma). Nature (London ), 202: 566 .

Jarrett, W.F.H., Crawford, E.M., Martin, W.B. and Davie, F., 1964b. Leukaemia in the cat. A virus-like particle associated with leukaemia (lymphosarcoma). Nature (London), 202: 567.

Jarrett, W.F.H., Jarrett, O., Mackey, L., Laird, H., Hardy, W.D., Jr. and Essex, W., 1973. Horizontal transmission of leukemia virus and leukemia in the cat. J. Natl. Cancer Inst., 51: 833841 .

Jarrett, W., Mackey, L., Jarrett, O., Laird, H. and Hood, C., 1974. Antibody response and virus survival in cats vaccinated against feline leukaemia. Nature (London), 248: 230-232.

Jerne, N.K., 1974. Towards a network theory of the immune system. Ann. Immunol. (Paris), 125C: $373-389$.

Legrain, P., Sanchez, P. and Buttin, G., 1985. Immune response induced by a single or several syngeneic monoclonal anti-ABPC48 anti-idiotypic antibodies: no predominant coexpression of ABPC48 idiotypes. J. Mol. Immunol., 22: 445-453.

Levine, A.M., Henderson, B.E., Dworsky, R., Ascher, M.S., Sheppard, H.W., Cullman, L.C., Hicks, D.R., Munson, C., Carlo, D.J., Abrahamson, J. and Salk, J., 1988. Response of HIV infected individuals with ARC to inoculation of gamma-irradiated HIV. In: IVth International Conference on AIDS, 12-16 June 1988, Stockholm, Sweden, Abstract 6567.

Lewis, M.G., Mathes, L.E. and Olsen, R.G., 1981. Protection against feline leukemia by vaccination with a subunit vaccine. Infect. Immunol., 34: 888-894.

Miller, R.A., Maloney, D.G., Warnke, R. and Levy, R., 1982. Treatment of B-cell lymphoma with monoclonal anti-idiotype antibody. N. Engl. J. Med., 306: 517-522.

Morein, B., Sundquist, B., Höglund, D., Dalsgaard, D. and Osterhaus, A., 1984. ISCOM, a novel structure for antigenic presentation of membrane proteins from enveloped viruses. Nature (London), 308: 457-460.

Norrby, E., 1983. Viral vaccines: the use of currently available products and future development. Arch. Virol., 76: 163-177.

Olsen, R.G., Hoover, E.A., Mathes, L.E., Heding, L.D. and Schaller, J.P., 1976. Immunization against feline oncornavirus disease using a killed tumor cell vaccine. Cancer Res., 36: 36423646.

Olsen, R.G., Hoover, E.A., Schaller, J.P., Mathes, L.E. and Wolff, L.H., 1977. Abrogation of resistance to feline oncornavirus disease by immunization with killed feline leukemia virus. Cancer Res., 37: 2082-2085.

Osterhaus, A., Weijer, K., UytdeHaag, F., Jarrett, O., Sundquist, B. and Morein, B., 1985. Induction of protective immune response in cats by vaccination with feline leukemia virus ISCOMs. J. Immunol., 135: 591-596.

Osterhaus, A., Weijer, K., UytdeHaag, F., Knell, P., Jarrett, O. and Morein, B., 1987a. Comparison 
of serological responses in cats vaccinated with two different FeLV vaccine preparations. Vet. Rec., 121: 260-261.

Osterhaus, A., Wagenaar, J., Weijer, K. and UytdeHaag, F., 1987b. Idiotype networks with immune response to feline leukemia virus. Monogr. Allergy, 22: 158-165.

Osterhaus, A.D.M.E., Bunschoten, E.J., Weijer, K. and UytdeHaag, F.G.C.M., 1988. Modulation of the immune system towards antiviral immune response using anti-idiotypic structures. In: C.A. Bona (Editor), Biological Applications of Anti-idiotypes. CRC Press, Boca Raton, FL, pp. $13-30$.

Overbaugh, J., Donahue, P.R., Quackenbush, S.L., Hoover, E.A. and Mullins, J.I., 1988. Molecular cloning of a feline leukemia virus that induces fatal immunodeficiency disease in cats. Science, 239: 906-910.

Pacitti, A.M., 1987. Latent feline leukaemia virus infection: a review. J. Small Anim. Pract., 28: 1153-1159.

Pedersen, N.C., Theilen, G.H., and Wunner, L.L., 1978. Safety and efficacy studies of live and killed feline leukemia virus vaccines. Am. J. Vet. Res., 40: 1120-1126.

Russell, P.H. and Jarrett, O., 1978. The specificity of neutralizing antibodies to feline leukaemia viruses. Int. J. Cancer, 21: 768-778.

Sanchez, P. and Legrain, P., 1985. The expression of a private idiotype requires pretreatment with non-complementary anti-idiotypic antibodies. J. Mol. Immunoi., 22: 1231-1236.

Sharpee, R.L., Beckenhauer, W.H., Baumgartener, L.E. and Haffer, K.N., 1986. Feline leukemia vaccine: evaluation of safety and efficacy against persistent viremia and tumor development. Compendium on Cont. Educ. Pract. Vet., 8: 267-277.

Shawler, C.L., Bartholomes, R.M., Smith, L.M. and Dillman, R.O., 1985. Human immune response to multiple injection of murine monoclonal IgG. J. Immunol., 135: 1530-1535.

Tax, W.J.M., Willems, H.W., Reekers, P.P.M., Capel, P.J.A. and Koene, R.A.P., 1983. Polymorphism in mitogenic effect of IgG1 monoclonal antibodies against T3 antigen on human cells. Nature (London), 304: 445-447.

UytdeHaag, F. and Osterhaus, A., 1985. Induction of neutralizing antibody in mice against poliovirus type II monoclonal anti-idiotypic antibody. J. Immunol., 134: 1225-1229.

UytdeHaag, F.G.C.M., Bunschoten, H., Weijer, K. and Osterhaus, A.D.M.E., 1986. From Jenner to Jerne: towards idiotype vaccines. Immunol. Rev., 90: 93-113.

Weijer, K. and Daams, J.H., 1976. The presence of leukaemia (lymphosarcoma) and feline leukaemia virus (FeLV) in cats in the Netherlands. J. Small Anim. Pract., 17: 649-659.

Weijer, K. and Daams, J.H., 1978. The control of lymphosarcoma/leukaemia and feline leukaemia virus. J. Small Anim. Pract., 19: 631-637.

Weijer, K., UytdeHaag, F. and Osterhaus, A., 1986a. Control of feline leukaemia virus infection by a removal programme. Vet. Rec., 119: 555-556.

Weijer, K., UytdeHaag, F.G.C.M., Jarrett, O., Lutz, H. and Osterhaus, A.D.M.E., 1986b. Postexposure treatment with monoclonal antibodies in a retrovirus system: failure to protect cats against feline leukemia virus infection with virus neutralizing monoclonal antibodies. Int. J. Cancer, 38: 81-87.

Weijer, K., UytdeHaag, F.G.C.M. and Osterhaus, A.D.M.E., 1988. Modulation of the immune response towards anti-FeLV immunity with anti-idiotype antibodies. In: L. Lasky (Editor), Technological Advances in Vaccine Development. Alan R. Liss, New York, NY, pp. 569-575.

Wong-Staal, R. and Gallo, R.C., 1985. Human T-lymphotropic retroviruses. Nature (London), 317: 395-403. 